\title{
Comparison of indicators of material circumstances in the context of an epidemiological study
}

Thomas Matukala Nkosi ${ }^{1,2}$, Marie-Elise Parent ${ }^{1,2,3}$, Jack Siemiatycki ${ }^{2,3}$, Javier Pintos ${ }^{3}$ and Marie-Claude Rousseau ${ }^{1,2,3^{*}}$

\begin{abstract}
Background: Since individual-level income is difficult to collect, investigators often rely on group-based measures derived from census data. No study has assessed the use of residential property values as an indicator of individual material circumstances. We aimed to compare two proxy indicators of material circumstances, one based on residential value and the other on median census tract income, to self-reported household income.
\end{abstract}

Methods: We used data from a case-control study (1996-2002), restricting analyses to 676 residents of the Island of Montreal for whom the three indicators were available. The degree of discrepancy between the residential value index, census income, and self-reported household income - each in 5 categories - was estimated, along with overall and weighted Kappas.

Results: When comparing residential value index and census income to self-reported household income, perfect concordance was observed for $38 \%$ and $30 \%$ of subjects, respectively; very good concordance, defined as $\leq 1$ category difference, was observed for $76 \%$ and $69 \%$ of subjects, respectively. When compared to self-reported household income, overall and weighted Kappas showed stronger agreement with residential value index (weighted Kappa $=0.37,95 \%$ Cl: 0.32, 0.42) than with census income (weighted Kappa $=0.25,95 \%$ Cl: 0.20, 0.30).

Conclusions: A residential value index may provide a measure of material circumstances that is closer to selfreported household income than the commonly used census income. Each indicator presents advantages and disadvantages, and their choice may depend on study objectives and feasibility.

\section{Background}

Material circumstances, best measured by income and wealth [1], are central in health research [2], since they can be an important determinant of health and health services use [3]. Income is a measure of the financial resources available at one point in time, whereas wealth measures the accumulation of material resources $[1,4]$. Education and occupation are often used in health research [5], but these factors provide information on socio-economic dimensions different from material circumstances and thus cannot be considered as surrogate measures of the latter [6].

\footnotetext{
* Correspondence: marie-claude.rousseau@iaf.inrs.ca

'Epidemiology and Biostatistics Unit, Institut National de la Recherche Scientifique (INRS)-Institut Armand-Frappier, 531, boulevard des Prairies, Laval, Québec, H7V 1B7, Canada

Full list of author information is available at the end of the article
}

While in theory, the best way to obtain individuals' income information is to ask them directly; in practice people often do not wish to report it or the quality of response is doubtful. The problem can be more acute for some sub-populations, for instance according to gender, age, or ethnic origin. This makes it very difficult for health researchers to collect reliable individual-level income information for the populations studied [2]. A commonly used surrogate measure of individual income is the area-based mean or median household income. Such measures are available for census areas and have been used 'inter alia' in Canada and in the U.S.A [7-11]. The validity of area-based measures derived from national census data as surrogates of individual income has been investigated [2,10-13]. Census-based measures have been reported to provide valid information that can be used in health research without being invalidated by concerns regarding ecological fallacy $[5,10]$. However, 
some have observed a substantial discrepancy between area-based and individual-level income measures, and suggested that caution should be used in interpreting results from studies in which area-based measures are used as proxies for individual and household income $[2,12,13]$.

Recently, authors from Montreal (QC, Canada) have suggested using area-based values of residential properties [14]. They derived average residential values for street blocks (areas smaller than census tracts) as an alternative approach to capture group-level information on material circumstances. In their study, Smargiassi et al [14] achieved a better control of confounding with area-based residential property values than with census tract-based income, suggesting that the former might capture material circumstances, which they refer to as socio-economic status, more accurately.

In order to further explore the potential usefulness of residential values in population-based research, we developed a residential value index, but at the individual rather than group level. Using data from a study conducted in Montreal, we aimed to compare this residential value index, as well as census-based median household income, to self-reported household income for classifying individuals' material circumstances.

\section{Methods}

\section{Study population}

We used data from a case-control study of environmental risk factors for lung cancer conducted in Greater Montreal in 1996-2002 [15]. This study included 738 men and 465 women with lung cancer diagnosed at all major Montrealarea hospitals, and residing in the Greater Montreal area, which includes the Island, as well as the North and South Shores. Population controls were randomly selected from electoral lists which are continually updated in Quebec, Canada. They are thought to represent nearly complete listings of Canadian citizens residing in the province. Controls were frequency-matched to the distributions of age, sex, and electoral districts (comprising about 40,000 electors) of lung cancer cases; there were 899 men and 614 women. Overall participation rate was $76 \%$, yielding 2,716 subjects. For this specific analysis, we restricted the study sample to the 2,003 participants who were residents of the Island of Montreal. Ethical approval was obtained from each participating institution, and all subjects provided an informed consent.

\section{Interviews}

Interviews were conducted by trained, bilingual (English/ French) interviewers between 1996 and 2002. Over 76\% of individuals responded for themselves, whereas surrogate respondents provided information for the other participants. Detailed information was collected on socio-demographic and lifestyle characteristics, including family income, residential history, ethnicity, country of origin, and lifetime smoking history, along with a wide range of potential environmental risk factors.

\section{Indicators of material circumstances}

The three indicators of material circumstances were derived from different sources. The first one, "selfreported household income", was elicited at interview with the following question: "What was the approximate total income for all household members from all sources, before income taxes, in an average year during the last 5 years?" This information was available for 730 (36\%) of the 2,003 study participants included in this analysis. The proportion of response to this question was much lower among men (15\%) than among women (71\%). For the purpose of our analyses, the original eight multiple choice answers were collapsed to five categories by combining some categories with very low numbers of subjects: $<\$ 20,000$ (30\% of sample); $\$ 20,000-\$ 29,999$ (24\%); $\$ 30,000-\$ 49,999$ (21\%); $\$ 50,000-\$ 69,999$ (13\%), and; $\geq \$ 70,000$ (12\%).

The second indicator, "residential value index", was derived from the 1995 residential property assessments of the City of Montreal (QC, Canada) that are used for municipal tax purposes. Residential values from 1995 were extracted using the participants' addresses at the time of interview. This older database was provided to us upon request, although the databases for the most recent property assessment rolls are publicly available online.

The property value reflects the market value on July 1 two years before the assessment role comes in effect. The market value is defined as the most probable selling price in a free and open market [16]. To determine the market value of a given property, the appraiser can use one of the three following methods, although the method used for a specific property is not recorded in the databases: 1) the comparison approach, using similar properties that have been sold; 2) the cost approach, which consists in adding a property's land value to the depreciated cost of the building (obtained by subtracting depreciation from the current replacement cost), and; 3) the income approach, based on capitalizing its net operating income at a rate stemming from similar properties sold [16]. The latter applies only to buildings with tenants or commercial property.

The municipal database of property value assessment includes all buildings and contains the monetary value attributed to each building and lot. It indicates the number of residential units in each building, and the proportion of the building's area identified as commercial, if any. To estimate the residential property value, the proportion of commercial space was subtracted from the total value of each building. For multiple residence buildings, at the exception of condominiums for which there was an 
individual evaluation per unit, there was no information available to attribute a specific value to different residences within one building. The residential value was then divided by the total number of residential units to estimate the average value of one unit. It was impossible to distinguish whether a residential unit was owned or rented, thereby preventing us to determine if the residence represented an expense or contributed to wealth. However, we assumed that there was a reasonably close relationship between the value of a given residential unit and the costs ensued to rent or own it and thus simply considered its value as a measure of what the participant was able to afford in terms of housing. For this study, we restricted our data collection of residential property values to residents of the Island of Montreal for whom these data were centralized in a database maintained by the City of Montreal, and easily accessible. Residential values were available for a total of 1,862 individuals, representing 93\% of the 2,003 study participants living within the Island of Montreal. The continuous values of this index were divided into 5 categories following the observed distribution for selfreported income: respectively $30 \%, 24 \%, 21 \%, 13 \%$, and $12 \%$ in categories 1 (lowest) to 5 (highest). The resulting cutoff points were: $\leq \$ 42,102 ; \$ 42,103-\$ 66,629 ; \$ 66,630$ $\$ 94,975 ; \$ 94,976-\$ 133,176 ; \geq \$ 133,177$.

Finally, the third indicator, "census income", was obtained from the 1996 Canadian census. A "census tract" is the elemental geographic unit used by Statistics Canada to report socio-demographic characteristics [17]. In 1996, there were 757 census tracts in the Montreal area (Census Metropolitan Area), each comprising an average of approximately 4,400 people [18]. Census tract data were extracted using the postal code for the subjects' residential address at the time of interview. The median household income for the census tract corresponding to each subject's residential postal code was used. This information was obtained for all 2,003 participants included in the current analyses. The resulting continuous values were categorized according to the observed distribution for self-reported income, as described previously. The resulting cutoff values for census income were: $\leq \$ 25,781 ; \$ 25,782-\$ 31,434 ; \$ 31,435-\$ 39,255$; $\$ 39,256-\$ 49,776 ; \geq \$ 49,777$.

\section{Statistical analysis}

Statistical analyses were restricted to 676 subjects residing on the Island of Montreal and for whom the three indicators of material circumstances were available, as depicted in Figure 1.

Firstly, the frequency distributions of the participants' selected characteristics and indicators of material circumstances were described. As mentioned previously, in order to compare the ranking of individuals according to the different indicators, the frequency distribution obtained for self-reported household income was used to categorize the residential value index and census income variables.

Secondly, the degree of discrepancy between selfreported household income and the other two indicators (residential value index, census income) was estimated. This was achieved by calculating the number of category differences ( 1 to 5 ) between each pair of indicators being compared.

Thirdly, pair wise correlations were estimated with the Spearman correlation coefficient, and agreement other than expected by chance was estimated with the overall and weighted Kappas and their 95\% confidence intervals. Similarly to the Kappa coefficient (K), the weighted Kappa $\left(K_{w}\right)$ is adjusted for chance agreement given the marginal distributions [19]. Whereas K considers only complete agreement, $\mathrm{K}_{\mathrm{w}}$ was developed for use with categorical scales, in order to account for partial agreement by allowing disagreements of varying magnitude to be weighted accordingly [19-21]. In our case, linear weights were used for $\mathrm{K}_{\mathrm{w}}$, thus attributing the same importance to a one-category difference, irrespective of whether it was between categories 1 and 2, or 4 and 5. Disagreements by a higher number of categories had a lower contribution to the $\mathrm{K}_{\mathrm{w}}$, such that perfect agreement had a weight of 1 , and differences of 1-4 categories had respective weights of $0.75,0.50,0.25$, and 0 [22]. Various arbitrary guidelines exist for the interpretation of the strength of agreement. According to Landis and Koch, $<0.00$ represents "poor" agreement, 0.00-0.20 "slight" agreement, 0.21-0.40 "fair" agreement, 0.41-0.60 "moderate" agreement, 0.61-0.80 "substantial" agreement, 0.811.00 "almost perfect" agreement [23]. Fleiss suggested that Kappa values $<0.40$ should be regarded as indicating "poor" agreement, 0.40-0.75 "fair to good" agreement, and $>0.75$ excellent agreement [24]. All analyses combined cases and controls after verification, in stratified analyses, that the case or control status had little influence on the results.

\section{Results}

Selected characteristics of participants are described in Table 1 . The sample included a majority of women, who were more likely than men to have provided their income. Most subjects were of French ancestry, born in Canada, and self-respondents to the interview. One fifth of the men and one quarter of the women had post-secondary education. More women than men had never smoked. According to information from the property value assessment, our study population lived mainly in housing with two or more residential units (72\%).

The self-reported household income variable was ordinal while the others were continuous. We demarcated the categorical boundaries for the residential value index 


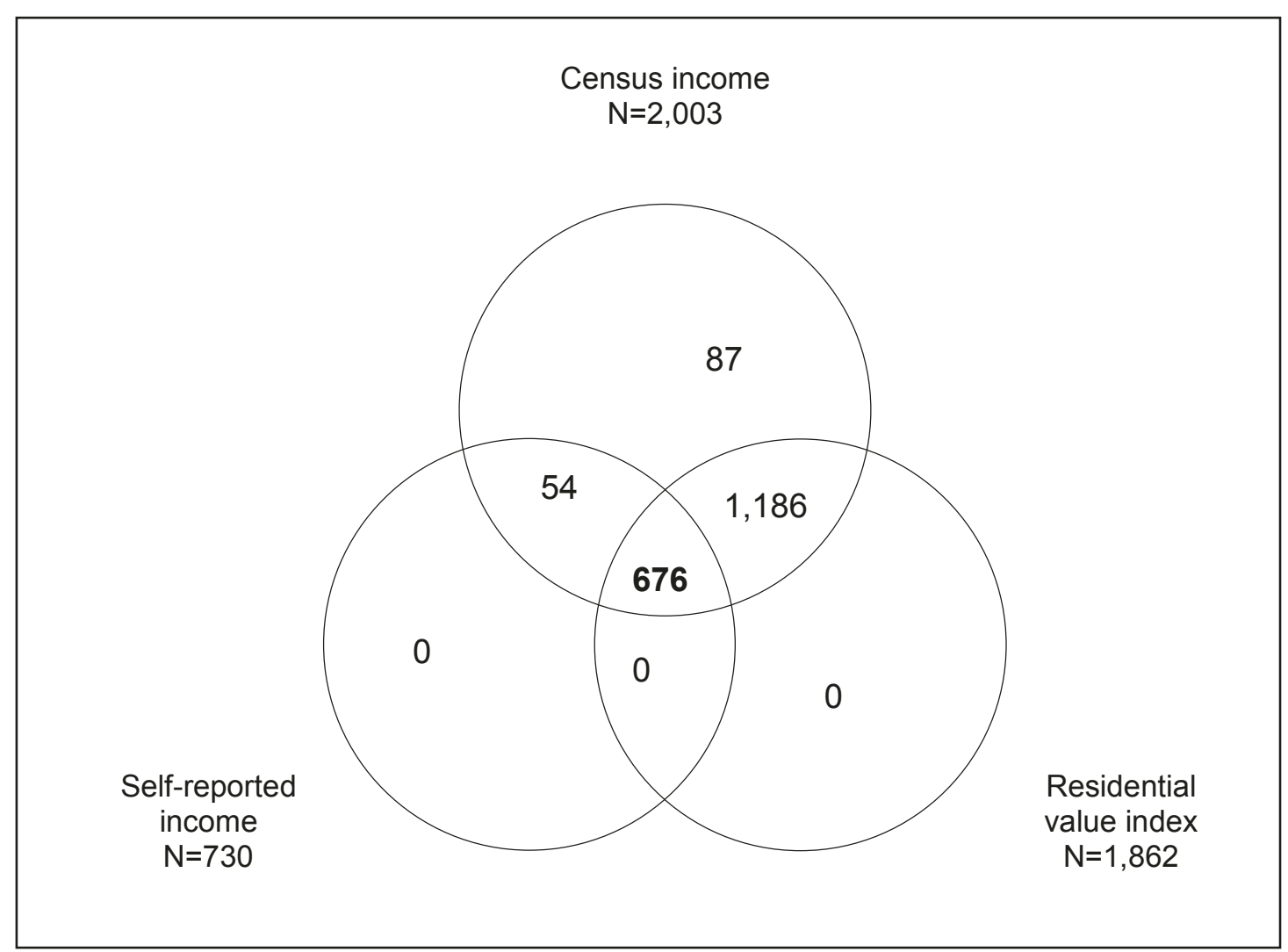

Figure 1 Venn diagram depicting the availability of the three indicators of material circumstances among study subjects $(\mathrm{N}=2,003)$.

and the census income index so that the marginal distributions of those variables would approximate that of self-reported household income (i.e., 30\%; 24\%; $21 \%$; $13 \% ; 12 \%)$. The resulting frequency distributions of the three indicators of material circumstances are presented in Table 2.

Table 3 presents the degree of discrepancy between five-category distributions of residential value index, census income and self-reported household income. Perfect concordance between residential value index and self-reported household income was observed for $38 \%$ of subjects, while the corresponding figure between census tract income and self-reported household income was $30 \%$. Very good concordance, defined as no more than one category difference, was observed for $76 \%$ of subjects when comparing the residential value index to selfreported household income and 69\% when comparing census tract to self-reported household income. In both of these comparisons, the discordant observations were equally distributed between under- and overestimation.

Spearman correlation coefficients and Kappa values for the five-category variables are presented in Table 4 . The correlation was stronger between residential value index and self-reported household income $\left(\mathrm{r}_{\text {Spearman }}=\right.$
$0.52)$ than between census and self-reported household incomes $\left(\mathrm{r}_{\text {Spearman }}=0.36\right)$. Overall and weighted Kappa values were relatively low $(<0.40)$, although weighted Kappa values were slightly higher, as expected. When compared to self-reported household income, both the overall and weighted Kappa showed stronger agreement for residential value index $\left(\mathrm{K}_{\mathrm{w}}=0.37,95 \%\right.$ CI: 0.32 $0.42)$ than for census income $\left(\mathrm{K}_{\mathrm{w}}=0.25,95 \% \mathrm{CI}: 0.20\right.$ 0.30 ). The absence of overlap in the confidence intervals both for the overall and weighted Kappas indicated stronger agreement when using residential value index, e.g., credible values based on the $95 \%$ CI were $0.32-0.42$ for $K_{w}$ for the agreement between residential value and self-reported income, whereas they varied from 0.20 0.30 for the agreement between census and self-reported incomes.

In our study, subjects were interviewed from 1996 to 2002. Census income was based on the 1996 Canadian census, whereas the residential value index was derived from the 1995 property assessment role from the City of Montreal. For subjects recruited towards the end of the study, the comparison could possibly have been improved by using the next census and property assessment role, both from 2001. To assess the impact of timing of data 
Table 1 Socio-demographic characteristics of study subjects

\begin{tabular}{|c|c|c|c|}
\hline Characteristic & $\begin{array}{c}\text { Males } \\
\mathrm{N}=177 \\
(\%)\end{array}$ & $\begin{array}{c}\text { Females } \\
\mathrm{N}=499 \\
(\%)\end{array}$ & $\begin{array}{c}\text { Total } \\
\mathrm{N}=676 \\
(\%)\end{array}$ \\
\hline \multicolumn{4}{|l|}{ Age (years) } \\
\hline $29-49$ & 5.6 & 12.8 & 10.9 \\
\hline $50-59$ & 12.4 & 30.9 & 26.0 \\
\hline $60-69$ & 57.1 & 37.5 & 42.6 \\
\hline$\geq 70$ & 24.9 & 18.8 & 20.4 \\
\hline \multicolumn{4}{|l|}{ Marital status } \\
\hline Married/cohabitating & 75.1 & 52.3 & 58.3 \\
\hline Single & 7.9 & 12.4 & 11.2 \\
\hline Separated/divorced & 13.0 & 17.4 & 16.3 \\
\hline Widowed & 4.0 & 17.8 & 14.2 \\
\hline \multicolumn{4}{|l|}{ Level of education } \\
\hline Primary & 38.4 & 27.5 & 30.3 \\
\hline High-school & 41.8 & 47.1 & 45.7 \\
\hline Post-secondary & 19.8 & 25.5 & 24.0 \\
\hline \multicolumn{4}{|l|}{ Ancestry } \\
\hline French & 69.5 & 70.9 & 70.6 \\
\hline Other & 30.5 & 29.1 & 29.4 \\
\hline \multicolumn{4}{|l|}{ Respondent } \\
\hline Self & 88.1 & 86.6 & 87.0 \\
\hline Other & 11.9 & 13.4 & 13.0 \\
\hline \multicolumn{4}{|l|}{ Country of origin } \\
\hline Canada & 78.5 & 80.4 & 79.9 \\
\hline Other & 21.5 & 19.6 & 20.1 \\
\hline \multicolumn{4}{|l|}{ Smoking status } \\
\hline Never & 11.3 & 31.6 & 26.5 \\
\hline Ex-smoker & 62.1 & 44.1 & 48.8 \\
\hline Current smoker & 26.6 & 24.0 & 24.7 \\
\hline
\end{tabular}

used for the census and residential value indicators, we carried out a sensitivity analysis excluding 256 participants interviewed after $1998(\mathrm{~N}=420)$. We also tested the impact of having included subjects for whom a proxy respondent provided the information. In both sensitivity analyses, the $\mathrm{K}_{\mathrm{w}}$ remained very similar suggesting that neither the use of 1995 property assessment role and 1996 census nor the use of proxy respondents had a strong influence on the results.

\section{Discussion}

In our study, there was a very good concordance (defined as no more than one category difference) for a majority of the participants between self-reported household income, and both the residential value index (76\%) and census income (69\%). Perfect concordance with self-reported household income was higher for residential value index $(38 \%)$ than for census income (30\%). In addition, although Kappa values were generally low, weighted Kappa values were relatively higher between
Table 2 Frequency distribution of indicators of material circumstances

\begin{tabular}{|c|c|c|c|}
\hline Indicators & $\begin{array}{c}\text { Males } \\
\mathrm{N}=177 \\
(\%)\end{array}$ & $\begin{array}{c}\text { Females } \\
\mathrm{N}=499 \\
(\%)\end{array}$ & $\begin{array}{c}\text { Total } \\
\mathrm{N}=676 \\
(\%)\end{array}$ \\
\hline \multicolumn{4}{|l|}{ Self-reported household income } \\
\hline Category 1: $<\$ 20,000$ & 20.3 & 33.7 & 30.2 \\
\hline Category 2: $\$ 20,000-\$ 29,999$ & 31.6 & 21.4 & 24.1 \\
\hline Category 3: $\$ 30,000-\$ 49,999$ & 26.6 & 19.0 & 21.0 \\
\hline Category 4: $\$ 50,000-\$ 69,999$ & 13.0 & 12.4 & 12.6 \\
\hline Category 5: $\geq \$ 70,000$ & 8.5 & 13.4 & 12.1 \\
\hline \multicolumn{4}{|l|}{ Residential value index } \\
\hline Category 1: $\leq \$ 42,102$ & 28.2 & 30.7 & 30.0 \\
\hline Category 2: $\$ 42,103-\$ 66,629$ & 27.1 & 22.8 & 24.0 \\
\hline Category 3: $\$ 66,630-\$ 94,975$ & 22.6 & 20.4 & 21.0 \\
\hline Category 4: $\$ 94,976-\$ 133,176$ & 13.6 & 12.8 & 13.0 \\
\hline Category 5: $\geq \$ 133,177$ & 8.5 & 13.2 & 12.0 \\
\hline \multicolumn{4}{|l|}{ Census income } \\
\hline Category 1: $\leq \$ 25,781$ & 29.9 & 30.7 & 30.5 \\
\hline Category 2: $\$ 25,782-\$ 31,434$ & 22.0 & 24.4 & 23.8 \\
\hline Category 3: $\$ 31,435-\$ 39,255$ & 24.9 & 19.2 & 20.7 \\
\hline Category 4: $\$ 39,256-\$ 49,776$ & 13.0 & 13.0 & 13.0 \\
\hline Category 5: $\geq \$ 49,777$ & 10.2 & 12.6 & 12.0 \\
\hline
\end{tabular}

residential value index and self-reported household income than between census and self-reported household incomes $(0.37$ versus 0.25$)$. This finding suggests that the residential value index may provide a slightly more accurate proxy for self-reported household income than census income, although the strength of agreement was in the "poor to fair" range. Our results also showed that for both residential value index and census income, values discrepant by more than one category were equally distributed between under- and overestimation of self-reported household income.

Overall, our study findings are in line with results from other similar studies suggesting relatively good concordance between self-reported household income and census tract income $[5,10]$. The census-based methodology was shown to be a valid and useful approach to overcoming the absence of socioeconomic data in most US medical records [11].

Nevertheless, when considering only the level of agreement between census and self-reported household incomes, we have observed relatively low levels of both overall and weighted Kappas. These findings are consistent with studies in which potential misclassification of income was investigated by comparing individual versus area-level measures of socioeconomic status, and that have suggested poor agreement between self-reported household income and census tract income $[2,12,13,25]$. 
Table 3 Proportion and number of subjects according to the degree of discrepancy between residential value index, census income, and self-reported household income $(\mathrm{N}=676)$

\begin{tabular}{|c|c|c|c|c|c|c|c|c|}
\hline \multirow[t]{3}{*}{ Comparison } & \multicolumn{7}{|c|}{ Number of category differences } & \multirow{3}{*}{ Tota } \\
\hline & \multicolumn{3}{|c|}{$\begin{array}{l}\text { Underestimation of Self- } \\
\text { reported household } \\
\text { income }\end{array}$} & \multirow{2}{*}{$\begin{array}{c}\text { Perfect concordance } \\
0 \\
\end{array}$} & \multicolumn{3}{|c|}{$\begin{array}{l}\text { Overestimation of Self- } \\
\text { reported household } \\
\text { income }\end{array}$} & \\
\hline & $\leq-3$ & -2 & -1 & & 1 & 2 & $\geq 3$ & \\
\hline \multicolumn{9}{|c|}{ Residential value index vs. Self-reported household income } \\
\hline$\%$ & 3.1 & 8.9 & 19.1 & 38.3 & 18.5 & 8.3 & 3.9 & 100 \\
\hline (n) & $(21)$ & $(60)$ & $(129)$ & (259) & $(125)$ & $(56)$ & $(26)$ & $(676)$ \\
\hline \multicolumn{9}{|c|}{ Census income vs. Self-reported household income } \\
\hline$\%$ & 5.3 & 9.6 & 20.6 & 29.6 & 19.1 & 10.9 & 4.8 & 100 \\
\hline (n) & (36) & (65) & (139) & (200) & (129) & (74) & (33) & (676) \\
\hline
\end{tabular}

It was suggested that the individual and census-based income might measure different constructs [12], and that aggregate measures should not be interpreted as individual ones [26].

An important finding from our study is that the residential value index was found to have slightly better agreement with self-reported household income than did census income. It might be partly due to the individual nature of both the residential value index and the selfreported income, as opposed to the area-level of the census income measurement. To our knowledge, our study is the first to use residential values at the individual level as an indicator of material circumstances. However, our results are in agreement with the observations from the study by Smargiassi and colleagues who used group-level residential values for a geographical area smaller than census tract, though not at the individual level [14].

\section{Limitations and strengths}

Limitations and strengths of this study are mainly related to the three indicators of material circumstances. We elected to use the self-reported household income as the base of comparison. However, we are cognizant that it is not necessarily a 'gold standard'. The self-reported household income was obtained from the participants' answers, and as such could be inaccurate or even biased. Many individuals are reluctant to disclose their income. Small differentials between true and self-reported household income would be expected to have little influence on results. Indeed, even if the participants slightly over- or underestimated their income, they would possibly remain within the same income category or be allocated in an adjacent one. However, any large discrepancy between true and self-reported household income could have introduced serious misclassification. In addition, selective response to the household income question could have introduced bias if agreement varied according to the factors that affected response. To verify this, we assessed whether census income and residential value differed according to sex and self-report (or not) of household income. When stratifying the entire study sample by sex and presence/absence of self-reported household income, the median household census income was $\$ 33,313$ and $\$ 33,312$ respectively among men and women who responded, \$30,300 among non-respondent men, and $\$ 30,950$ among non-respondent women, suggesting a slightly but not markedly lower income among those who did not respond to the household income question, and little difference according to sex. There were no differences in distributions of residential value by sex and by presence/absence of self-reported household income (data not shown). This suggests that the relatively low response rate to the household income question and the larger proportion of women who responded is not likely to have strongly influenced our results.

Census tracts are demarcated by Statistics Canada with a view to creating socially homogeneous units. Still, there is some financial heterogeneity within census

Table 4 Correlation and agreement between residential value index, census income, and self-reported household income $(N=676)$

\begin{tabular}{|c|c|c|c|}
\hline & $\begin{array}{c}\text { Spearman correlation } \\
\text { coefficient }\end{array}$ & $\begin{array}{l}\text { Overall Kappa } \\
(95 \% \mathrm{Cl})\end{array}$ & $\begin{array}{l}\text { Weighted Kappa } \\
(95 \% \mathrm{Cl})\end{array}$ \\
\hline $\begin{array}{l}\text { Residential value index vs. Self-reported household } \\
\text { income }\end{array}$ & 0.52 & $\begin{array}{c}0.21 \\
(0.16-0.25)\end{array}$ & $\begin{array}{c}0.37 \\
(0.32-0.42)\end{array}$ \\
\hline Census income vs. Self-reported household income & 0.36 & $\begin{array}{c}0.09 \\
(0.05-0.14)\end{array}$ & $\begin{array}{c}0.25 \\
(0.20-0.30)\end{array}$ \\
\hline
\end{tabular}


tracts; even neighbors may have different financial means. Thus median census tract income is certainly an imperfect indicator of the financial means of each individual in the census tract.

For municipalities in which property assessment rolls exist and can be publicly accessed, there are a number of advantages from using the residential value information. The residential municipal evaluation is intrinsically adjusted in terms of the degree of investment in maintaining the property, so a higher value will reflect, to a certain extent, the availability of funds for maintenance. The residential value index for participants is expressed as the average value of one residential unit. It has the advantage of taking into account the disparities in the quality of neighborhood and the housing conditions that prevail [27]. Also considered are the specific characteristics of the neighborhood and several factors such as the size of the house, type and materials used in its construction, physical environment, proximity to public transportation, shops and services, noise impacts, access to major roads and hospitals, which contribute to determine the value of a property. The residential value index is thus an indicator of great interest, because it represents the residential choice which is determined, in part, by the economic power of the household [27].

A few issues deserve attention with respect to the residential value index. Firstly, we could not assign a value to persons residing in retirement and other community homes. However, since we were able to document the residential value for $93 \%$ of those living on the Island of Montreal, these represent a small fraction of the entire population. Secondly, to our knowledge, the specific method used by the appraiser to establish the value of a given property is not documented in the publicly available databases. It is unclear whether the choice of appraisal method had an impact on the property values per se. Thirdly, for this study we restricted our sample to residents of the Island of Montreal for whom residential values were readily available as a result of a recent administrative restructuring and city merger. This information is available in other municipalities, and thus could eventually be gathered for the entire study. The Island of Montreal contains a high proportion of buildings with multiple units, many of them rentals, for which residential value is more difficult to assign. For this reason, we believe that our estimates of agreement are more conservative than if we had been able to also consider the suburbs surrounding the Island of Montreal, comprising a greater proportion of single unit dwellings. Fourthly, a limitation of the residential value index is that it was not possible to distinguish the surface area of each unit for buildings with more than one unit. Misclassification could have resulted, especially for residents of multiple dwelling buildings who were attributed the average value of a dwelling. Finally, no distinction could be made between owners and renters, possibly leading to an underestimation of financial availability for the former. Some of these potential limitations could be mitigated by collecting additional information at the time of interview concerning the owner or renter status of the subjects and the size of the dwelling when the property is part of multiple units.

The public availability of residential property values is a local administrative matter, but a non-exhaustive search on the internet allowed us to identify quite a few large cities, counties and countries where such data are accessible online [28-30] or where they exist and could possibly be accessed after an official request [31-35]. Since individual residential property values have the potential to approximate individual income at least as well as either census-based income or group-level residential property values, it appears to be a potentially valuable source of information that investigators should consider collecting, instead of or in addition to other indicators of material circumstances.

\section{Conclusions}

Overall, our results suggest that using a residential value index may provide a measure of material circumstances that is closer to self-reported household income than the commonly used census income. Each indicator presents, however, advantages and disadvantages and their use may depend on study objectives and feasibility. In some situations a choice may be indicated, whereas in others the use of several complementary indicators will allow for a more comprehensive measurement of material circumstances, taking into account both income and wealth.

Finally, given the generally low Kappa values observed in our study, further research on the validity of a residential value index as an individual indicator of material circumstances and comparisons between individual and area-level residential values are warranted.

\section{Acknowledgements}

We are indebted to Bernard Côté from the City of Montreal for his assistance in getting access to residential values information. We thank Alexandre Liautaud and Katia DeMarco for their help in gathering the residential values and Marie Désy for her assistance on the statistical analysis. Lesley Richardson contributed to the design of the original study, and she developed and coordinated the data collection methods. A large number of research assistants and interviewers participated, including Marie-Claire Goulet, Jerome Asselin, and Sally Campbell. This study was supported by research and personnel support grants from the National Health Research and Development Program from Health Canada, the National Cancer Institute of Canada, the Institut de recherche en santé et sécurité au travail du Québec, the Fonds de la recherche en santé du Québec (FRSQ), and the Canadian Institutes of Health Research (CIHR). MEP is the recipient of a salary award from the FRSQ. JS holds the Guzzo-Cancer Research Society (CRS) Chair in Environment and Cancer at University of Montreal. MCR is the recipient of a New Investigator Award from the CIHR. 


\section{Author details}

${ }^{1}$ Epidemiology and Biostatistics Unit, Institut National de la Recherche Scientifique (INRS)-Institut Armand-Frappier, 531, boulevard des Prairies, Laval, Québec, H7V 1B7, Canada. ${ }^{2}$ Department of Social and Preventive Medicine, Université de Montréal, Montréal, Québec, Canada. ${ }^{3}$ Université de Montréal Hospital Research Centre (CRCHUM), Montréal, Québec, Canada.

\section{Authors' contributions}

All authors have contributed substantially to the manuscript. TMN was responsible for data analysis and interpretation, and for writing the first version of the manuscript. MEP and MCR were involved in the conception and design of the analytical strategy, interpretation of the data and critical revisions of the manuscript. JP provided the initial idea for the analysis, participated to the conception and design of the analytical strategy, and contributed critical revisions to the manuscript. JS conceived and realized the original study, was involved in data interpretation, and provided critical revisions to the manuscript. All authors have approved the final version of the manuscript.

\section{Competing interests}

The authors declare that they have no competing interests.

Received: 8 December 2010 Accepted: 18 July 2011

Published: 18 July 2011

\section{References}

1. Galobardes B, Lynch J, Smith GD: Measuring socioeconomic position in health research. Br Med Bull 2007, 81-82:21-37.

2. Hanley GE, Morgan S: On the validity of area-based income measures to proxy household income. BMC Health Serv Res 2008, 8:79.

3. Adler NE, Boyce WT, Chesney MA, Folkman S, Syme SL: Socioeconomic inequalities in health. No easy solution. JAMA 1993, 269:3140-3145.

4. Lynch J, Kaplan G: Socioeconomic position. In Social Epidemiology.. 1 edition. Edited by: Berkman LF, Kawachi I. Oxford: Oxford University Press; 2000:13-35.

5. Krieger N, Williams DR, Moss NE: Measuring social class in US public health research: concepts, methodologies, and guidelines. Annu Rev Public Health 1997, 18:341-378.

6. Galobardes B, Morabia A, Bernstein MS: Diet and socioeconomic position: does the use of different indicators matter? Int J Epidemiol 2001, 30:334-340.

7. Siemiatycki J: A comparison of mail, telephone, and home interview strategies for household health surveys. Am J Public Health 1979, 69:238-245.

8. Siemiatycki J, Campbell S, Richardson L, Aubert D: Quality of response in different population groups in mail and telephone surveys. Am J Epidemiol 1984, 120:302-314.

9. Siemiatycki J, Wacholder S, Richardson L, Dewar R, Gerin M: Discovering carcinogens in the occupational environment. Methods of data collection and analysis of a large case-referent monitoring system. Scand J Work Environ Health 1987, 13:486-492.

10. Krieger N: Women and social class: a methodological study comparing individual, household, and census measures as predictors of black/white differences in reproductive history. J Epidemiol Community Health 1991, 45:35-42.

11. Krieger $\mathrm{N}$ : Overcoming the absence of socioeconomic data in medical records: validation and application of a census-based methodology. Am J Public Health 1992, 82:703-710.

12. Southern DA, McLaren L, Hawe P, Knudtson ML, Ghali WA: Individual-level and neighborhood-level income measures: agreement and association with outcomes in a cardiac disease cohort. Med Care 2005, 43:1116-1122.

13. Demissie K, Hanley JA, Menzies D, Joseph L, Ernst P: Agreement in measuring socio-economic status: area-based versus individual measures. Chronic Dis Can 2000, 21:1-7.

14. Smargiassi A, Berrada K, Fortier I, Kosatsky T: Traffic intensity, dwelling value, and hospital admissions for respiratory disease among the elderly in Montreal (Canada): a case-control analysis. J Epidemiol Community Health 2006, 60:507-512.

15. Pintos J, Parent ME, Rousseau MC, Case BW, Siemiatycki J: Occupational exposure to asbestos and man-made vitreous fibers, and risk of lung cancer: evidence from two case-control studies in Montreal, Canada. J Occup Environ Med 2008, 50:1273-1281.

16. City of Montreal: The assessment roll. [http://ville.montreal.qc.ca/portal/ page?_pageid=3137,3741720\&_dad=portal\&_schema=PORTAL].

17. Statistics Canada, Census geography. [http://www12.statcan.gc.ca/censusrecensement/2006/ref/dict/overview-apercu/pop6-eng.cfm\#04].

18. STATISTIQUE CANADA. Profil des secteurs de recensement, RMR de Montréal. Recensement de 1996. Produit n 95F0183XDB96006 au catalogue. .

19. Cohen J: Weighted kappa: nominal scale agreement with provision for scaled disagreement or partial credit. Psychol Bull 1968, 70:213-220.

20. Streiner DL, Norman GR: Biostatistics: The Bare Essentials Saint-Louis (Missouri): Mosby; 1994.

21. Streiner DL, Norman GR: Health measurement scales: A pratical guide to their development and use. Second edition. Oxford (New York): Oxford University Press; 1996.

22. Sim J, Wright CC: The kappa statistic in reliability studies: use, interpretation, and sample size requirements. Phys Ther 2005, 85:257-268.

23. Landis JR, Koch GG: The measurement of observer agreement for categorical data. Biometrics 1977, 33:159-174.

24. Fleiss JL: Statistical methods for rates and proportions. 2 edition. New York: John Wiley; 1981.

25. Diez-Roux AV, Link BG, Northridge ME: A multilevel analysis of income inequality and cardiovascular disease risk factors. Soc Sci Med 2000, 50:673-687.

26. Geronimus AT, Bound J: Use of census-based aggregate variables to proxy for socioeconomic group: evidence from national samples. Am J Epidemiol 1998, 148:475-486.

27. Paré S: Le rôle des agents immobiliers dans la ségrégation résidentielle ethnique: Processus et mécanismes de production. Université de Montréal, Département de sociologie; 1998.

28. The City of Edmonton: Resident tax and assessment. [http://www. edmonton.ca/for_residents/residential_property_taxes/assessment-mapsproperty-value.aspx].

29. Washington County Assessor. [http://www.washington.minnesotaassessors. $\mathrm{com} / \mathrm{l}$.

30. UK Valuation Office Agency. [http://www.voa.gov.uk/corporate/CouncilTax/ index.html].

31. The City of Toronto: Access to assessment rolls. [http://www.toronto.ca/ assessment/index.htm].

32. Statistics Netherlands, Property Assessment Act. [http://www.cbs.nl/en$\mathrm{GB} / \mathrm{menu} /$ methoden/toelichtingen/alfabet/p/property+assessment+act.htm].

33. Région de Bruxelles-Capitale: Cadastre [in French]. [http://www.belgium. be/fr/logement/construire_et_renover/revenu_cadastral/].

34. Ministère Français du Budget, des Comptes publics, de la Fonction publique et de la Réforme de l'État: Taxe d'habitation [in French]. [http:// www.impots.gouv.fr/portal/dgi/public/particuliers.impot: jsessionid=F4NFI2MTVO3NPQFIEMQSFE4AVARW4IV1? espld=1\&pageld=part_taxe_habitation\&impot=TH\&sfid=50].

35. Ministère Français du Budget, des Comptes publics, de la Fonction publique et de la Réforme de l'État: Collectivités locales - Cadastre et domaine [in French]. [http://www.impot.gouv.fr/portal/dgi/public/ collectivites.impot?espld=3\&pageld=coll_cadastre_domaine\&sfid=630].

\section{Pre-publication history}

The pre-publication history for this paper can be accessed here: http://www.biomedcentral.com/1471-2288/11/108/prepub

doi:10.1186/1471-2288-11-108

Cite this article as: Nkosi et al:: Comparison of indicators of material circumstances in the context of an epidemiological study. BMC Medical Research Methodology 2011 11:108. 